\title{
Chapter 2 Theoretical framework and state of art on the implementation of a real time PCR for the Escherichia coli Salmonella spp detection
}

\author{
Hernando Bolivar Anillo \\ Universidad Simon Bolivar, Colombia \\ hbolívar1@unisimonbolívar.edu.co \\ Zamira Soto Varela \\ Universidad Simon Bolivar, Colombia \\ zsoto1@unisimonbolívar.edu.co \\ Christian Orozco Sanchez \\ Universidad Simon Bolivar, Colombia \\ Corporacion Universitaria de Ciencias Empresariales, \\ Educacion y Salud - Corsalud. \\ Barranquilla, Colombia. \\ christian8413@hotmail.com \\ Camila Pichon Gonzalez \\ Universidad Simón Bolívar, Colombia \\ camilapichon21@gmail.com \\ Bertha Granados Pantoja \\ Universidad Simon Bolivar, Colombia \\ bgranados3@unisimon.edu.co
}

Molecular methods such as polymerase chain reaction are considered an alternative technology in microbiological diagnosis that overcomes some current limitations of traditional culture methods, as they offer the possibility of reducing the test time, improving detection sensitivity and specificity and identify several pathogens at the same time. For PCR implementation it is necessary to take into account certain principles and theoretical bases of the processes that are carried out in the method development for water 
microbiological control; starting from bacterial concentration methods, followed by the basis of bacterial DNA extraction and finally the basis of the PCR technique, specifically with the real-time variant.

\section{BACTERIAL CONCENTRATION METHODS}

In the microbiology laboratory it is very difficult to detect microorganisms that are in small numbers and besides being accompanied by a microflora and found in a complex matrix (8). Therefore, separation and concentration techniques have evolved to perform a specific detection of microorganism to be investigated, thereby avoiding false negative results (9). The general purpose of the separation and concentration process is to obtain the target cell in high number and separate them from the matrix components that negatively impact its detection, with the consequent reduction in the sample volume and heterogeneity $(10,11)$. Concentration is an important step in improving the detection sensitivity of microbial contaminants, especially by molecular tools that use samples with very small volumes (12).

Concentration methods can be performed under two strategies, those based on non-specific approaches depending on physical and/or chemical principles and those based on specific approaches that are selective and based on ligands with target cell specificity (10). Non-specific approaches include centrifugation, filtration, ion exchange resins, and dielectrophoresis. On the other hand the immunomagnetic separation and flow cytometry stand out among the specific approaches.

Centrifugation is a separation method that uses the rotation around a fixed axis (10). The force generated during rotation drives the suspended particles in a liquid to settle, which depends on several parameters including cell diameter, particle density and solution, volume, angle and spin speed $(10,11)$. Centrifugation has been classified according to the centrifugal force applied in low speed centrifugation (maximum $8000 \mathrm{x}$ g), high speed 
Theoretical frameworks and state of the art on the implementation of a real time PCR for the Escherichia coli quantification and Salmonella spp detection

$(8000-60,000 \times \mathrm{g})$ and ultracentrifugation (maximum 700,000 x g) (11). Variables manipulation, such as solution density and particle size have allowed the creation of alternative centrifugation methods such as differential and density gradient centrifugation (11).

Differential centrifugation consists of a gradual increase in the centrifugation speed, sedimenting first the component of larger size and high density, followed by the small size and low density particles. Density gradient centrifugation is performed using a compound (sucrose, ficol and/or percol) that forms a density gradient in the tube in which the particles migrate differentially during centrifugation to the point where their density is in equilibrium with that of the solution, forming bands that can be removed for future analysis (10).

Membranes have traditionally been used to separate substances based on size (13). Filtration is a physical concentration method that consists of removing organisms from a sample, passing the sample through filters with different sizes pores. Despite its easy realization, filtration is very sensitive to the matrix, where large particles tend to clog the filter, inhibitory compounds of PCR could be concentrated with the microorganisms and some filters could inhibit the nucleic acids amplification, which limits the use of this technique (10). However, tangential flow filtration is a technique that reduces filter clogging through parallel flows of tangent fluids to the filter surface, which allows the microorganisms to be concentrated in an efficient, aseptic and rapid manner using a recirculating filtration closed system that allows to handle high volumes of sample that in the case of the water is between 1-1000 L $(14,15)$.

The particles electrokinetic movement refers to the migration of these charged or non-electrically charged particles into a medium in the presence 
Many microorganisms have a negative net charge at $\mathrm{pH} \geq 5$ due to the ionization of the carboxyl and amino groups of the cell wall (11). The ion exchange resins are composed of small porous polymer spheres that are bonded with positively or negatively charged groups (10). Positive charge electrical exchange resins attract negatively charged bacteria that are adsorbed and can subsequently be eluted by altering $\mathrm{pH}$ (10).

Immunomagnetic separation is a specific concentration technique consisting of beads with a core of magnetic material and a polymer group conjugated to an antibody on the surface, known as immunomagnetic beads (17). The immunomagnetic beads can bind to the bacterium and form a bead-bacteria complex which can subsequently be easily separated from the matrix where it is located and concentrated to a smaller volume by applying a magnetic field (18). The immunomagnetic separation specificity is based on the fact that the monoclonal antibodies bound to the immunomagnetic beads are directed against a specific antigen of the bacterium of interest (11).

Although flow cytometry is not a concentration method per se, it is a technique that provides information about a single-cell culture by analyzing intrinsic and extrinsic parameters based on the scattering of 
Theoretical frameworks and state of the art on the implementation of a real time PCR for the Escherichia coli quantification and Salmonella spp detection

light or fluorescent signals (19). The cells are suspended in a liquid and produce a signal when they pass individually through a beam of light; some cytometers are able to physically separate cell subsets based on their cytometric characteristics, so for specific cell detection these must be labeled with fluorescent molecules $(20,21)$.

\section{BACTERIAL DNA EXTRACTION}

In microbiological diagnosis by PCR, DNA extraction is the first step once the bacteria are concentrated, isolated or grown from a sample. Currently, there are several extraction methodologies and it is necessary for molecular biologists to select the technique that best suits their needs (22).

In the case of the PCR technique, the DNA corresponds to be the analyte; therefore, the starting point in the diagnostic methods is the realization of a correct obtaining process of this molecule from the biological material (23), so that a high good quality DNA amount is reached; which means, not being degraded and is free of compounds that may be inhibitors of the technique (24).

The general procedure for extracting DNA from the bacterial concentrate consists of three consecutive steps: the first one is cell lysis, the second corresponds to the degradation of the DNA-associated protein fraction and the last to the DNA purification (23).

In cell lysis the degradation of the bacterial wall and the cell membrane is carried out and in this way the nucleic acid is released from the cells; for this purpose, detergents such as Triton and sodium docedil sulfate (SDS) (22), chaotropic salts that help to denature membrane proteins (23) and enzymes such as lysozyme are used, which act to destabilize the cell wall by breaking the glycosidic bonds between the polysaccharides $\mathrm{N}$-acetyl-glu- 
cosamine (NAG) and N-acetylmuramic acid (NAM). Incubation with the enzyme is performed for $1-2$ hours at $37^{\circ} \mathrm{C}(25)$. The lysis stage is critical and must be aggressive enough to achieve rupture of the cell membrane without damaging the DNA (22).

The second extraction step corresponds to degradation of the DNA-associated protein fraction, which can be done by the addition of an enzyme such as proteinase $\mathrm{K}$ (23), as well as using organic solvents such as phenol and chloroform that allow proteins denaturation. Phenol must be double distilled, equilibrated and protected from oxidation by adding 8-hydroxyquinoline. On the other hand, isoamyl alcohol is added to the chloroform in a ratio of 24: $1(\mathrm{v} / \mathrm{v})$ in order to prevent foaming and facilitate separation of the aqueous and organic phases (26). Proteins separation is enhanced by the use of salts such as ammonium acetate, sodium acetate and sodium chloride at high concentrations (22).

Chloroform-isoamyl alcohol (24:1) is widely used in extraction methods because of the quantity and quality of the obtained DNA, in this case the extraction is considered liquid-liquid, which is based on the separation of a mixture of molecules based on the solubility difference of each one of them in two immiscible liquids (27). With the use of chloroform-isoamyl alcohol after cell lysis and proteins denaturation, an organic phase is generated in the lower part of the tube where lipids, proteins and cellular debris are found and an aqueous phase in the upper part where nucleic acids and other small water-soluble molecules are. At the interface, most of the proteins are located, due to their content in hydrophobic and hydrophilic amino acids (22).

The final purification step in turn consists of three phases; the first is the DNA precipitation that being insoluble in alcohol, precipitated with cold 
Theoretical frameworks and state of the art on the implementation of a real time PCR for the Escherichia coli quantification and Salmonella spp detection

ethanol or isopropanol and then recovered by centrifugation (23). When isopropanol is employed the process can be accelerated and precipitation can be performed at room temperature (22). Some techniques improve precipitation by using monovalent cations at concentrations of 0.1 to 0.5 $\mathrm{M}$ (26). The second stage is the washing of DNA with 70 \% ethanol, at this concentration the DNA is kept precipitated and the remaining water allows the dissolution of the salts. After washing, the obtained pellet is dried for alcohol evaporation (22). In the last phase the resuspension of the sediment obtained is carried out with solutions that ensure its preservation as sterile and DNA se-free water, or with Tris EDTA (TE) buffer. The amount of solution used should be minimal to maintain adequate but sufficient concentration to achieve complete DNA dissolution (22).

Due to the laborious processes of bacterial DNA extraction and the toxicity of organic solvents, extraction kits are now widely used that are based on the same principles, allowing the process to be simpler and faster and obtainable a higher quality DNA (28).

An example of a commercial kit is PureLink ${ }^{\mathrm{TM}}$ Genomic DNA mini Kit, which allows rapid and efficient purification of genomic DNA from breast, tissue, mouse, blood and bacteria samples. This kit is based on the selective binding of DNA to a silica membrane in the presence of chaotropic salts. For lysis of cells and tissues proteinase $\mathrm{K}$ at $55{ }^{\circ} \mathrm{C}$ is used with a digestion buffer that helps protein denaturation and enzyme activity and RNase is also used to remove RNA; then this cell lysate is mixed with ethanol and a binding buffer that allows the DNA to adhere to the silica membrane located on a column, the impurities are removed with two washing buffers and the DNA is eluded in a low salinity buffer (29). 


\section{REAL-TIME PCR}

For years, science has focused its research on finding tools and mechanisms directed to the study of DNA, from this have been developed numerous techniques based on molecular bases, such as the PCR technique, whereby millions of specific DNA copies sequence are obtained through the DNA polymerase enzyme for the purpose of using them for a wide variety of purposes (30).

Real-time PCR is a variant of PCR; where the term "real time" refers to the detection of amplified products in each cycle of the reaction (31). This variant is of the quantitative type, since it is possible to quantify the amount of DNA in the sample as the amount of fluorescence of the amplified product labeled (32). Thus, the real-time PCR technique combines amplification and detection in the same step, by relating the amplified product generated in each cycle with a fluorescence intensity signal (33). The emission of produced fluorescence in the reaction is proportional to the amplified DNA amount, which allows knowing and recording the kinetics of the amplification reaction (34).

This technique has the advantage of reducing the diagnostic time, since the amplification and the visualization of the products are carried out simultaneously; obtaining the results in two hours, unlike the conventional PCR that requires 2-3 hours to complete the cycles of amplification, added to the time for products visualization by the electrophoresis. Another advantage is the high specificity and the wide detection range that can be from $2.5 \mathrm{fg}$ to $25 \mathrm{pg}(35,36)$. However, it should be recognized that the presence of inhibitors in different environmental samples and the lack of data on the viability of microorganisms may be some of the problems that must be taken into account when implementing this technique (31). To solve the 
Theoretical frameworks and state of the art on the implementation of a real time PCR for the Escherichia coli quantification and Salmonella spp detection

problem of inhibitors, an internal control is used that is added at the time of DNA extraction and is amplified while the target segment is detected independently (37).

For the development of real-time PCR, in addition to the reagents used in conventional PCR, it is necessary to use a fluorophore and a device capable of detecting fluorescent signals, a fluorometer to monitor the progress of the amplification reaction, as well as hardware and software for data capture and analysis (35). Fluorescence monitoring generates a typical curve consisting of an exponential phase where the product doubles exactly in each cycle and a linear plateau phase where the reagents are consumed and the reaction is stopped. There is also a baseline that corresponds to the basal level or background of fluorescence during the first cycles of the PCR and the threshold that is the fixed fluorescence level above the baseline where the early exponential phase begins (37).

In this kinetics it is important to highlight the $\mathrm{Ct}$ value ( $\mathrm{Cp}$ or $\mathrm{Cq}$ ), which is the cycle number at which the fluorescence exceeds the threshold and is detected, this is inversely proportional to the initial concentration of target DNA or RNA present in the Sample (38). From this principle can be generated quantitative data, producing a standard curve that relates the value of Ct obtained with the initial amount of DNA or number of gene copies to be detected. In the case of the microbial load determination of a sample, the standard curve can be made from serial dilutions of established bacterial density (UFC/mL), known concentrations of synthetic oligonucleotides (copies $/ \mathrm{mL}$ ) or cloned plasmids concentrations. The curve is then generated with the amplification data obtained from these standards and the linear regression analysis of them (38).

The fluorescence detection systems used in real-time PCR can be inter- 
calators and probes specific for DNA fragments (39). Intercalating agents are fluorochromes that increase the fluorescence emission when bound to double-helical DNA; one of the most used agents is SYBR Green, which provides the advantage of optimizing reaction conditions, in addition to being more economical, but has the disadvantage of being less specific (37).

The specific probes are based on the FRET (Fluorescence Resonance Energy Transfer) principle, which is based on the transfer of energy between two fluorophores: a donor (reporter) and an acceptor (quencher), which emit fluorescence at different wavelengths. When the reporter and the quencher are close, the quencher absorbs all of the reporter's fluorescence, but when separated, the reporter's fluorescence cannot be absorbed by the quencher and can therefore be detected (30).

The most commonly used probe is the taqMan probe, also known as the 5 ' nuclease probe, because it uses the 5' 3' exonuclease activity of the Taq polymerase to generate the fluorescence signal. The system consists of probe specific use for the gene of interest marked with two fluorophores, a reporter attached to the 5' end such as 6-carboxyfluorescein (FAM) and a 3 ' terminator such as 6-carboxytetramethylrodamine (TAMRA); Furthermore, it possesses a phosphate molecule which binds to the 3-thymine terminal residue to prevent the extension of the bound probe during amplification. The 5' exonuclease activity of the DNA polymerase cuts nucleotides from the probe during amplification, whereby the fluorophores are separated and the fluorescence signal is observed (40).

\section{IMPLEMENTATION OF PCR FOR THE DETECTION OF PATHOGENIC BACTERIA IN WATER}

Waterborne diseases outbreaks are often not reported in developing countries due to the lack of systematic studies. Microorganisms presence 
Theoretical frameworks and state of the art on the implementation of a real time PCR for the Escherichia coli quantification and Salmonella spp detection

such as Salmonella spp. in water samples provide undeniable evidence of the poor microbiological quality of an urban public service, thus demonstrating the lack of a systematic and regulated mechanism for surveillance and pathogens monitoring in potable water supply, which is a necessity for minimizing waterborne diseases problems (41).

In developing countries, pathogens as Salmonella spp. are rarely reported in waterborne outbreaks despite being frequently detected in surface waters, including recreational waters and waters used for irrigation or as a source of drinking water. Increasingly, more and more resistant strains to multiple drugs are present, which represent a greater risk to human health and may contribute to the spread of drug resistance (42). These limitations can place public health at significant risk, leading to substantial monetary losses in health care, as well as costs associated with reduced productivity in the area affected by the outbreak, and the costs held by water quality control departments (43).

Pathogenic bacteria have been detected for a long time using methods based on classical culture, including growth in selective media followed by morphological, biochemical and immunological confirmation; however, these culture methods are time consuming and many bacteria transmitted by water can enter a viable but non-cultivable state in the environment without losing their virulence. In order to solve this problem, methods based on DNA amplification, such as the PCR, have been developed that can improve pathogens detection in the environment (44). For example, in most cases, culture is the standard method and the most specific diagnostic procedure for legionellosis; however, this technique requires a lot of time due to the slow growth rate of this bacterium, the inability to detect non-cultivable viable bacteria and the difficult isolation in contaminated samples with high levels of accompanying flora $(45,46)$. 
New technologies based on real-time PCR (RT-PCR) have emerged in recent years as a leading technology for the rapid detection and quantification of pathogenic microorganisms in different media: food products, clinical samples and water, all due to their high degree of sensitivity and specificity, introducing the possibility of a faster detection of the target microorganism in real time, without the need for additional time to detect the PCR products by electrophoresis (43,47); however, molecular identification is used under circumstances such as the species characterization with aberrant biochemical characteristics, recurrent diseases, resistance patterns, for purposes of public health surveillance and publications (48).

\section{Salmonella spp.}

The genus Salmonella, is a member of the family Enterobacteriaceae (49). Are Gram-negative bacilli, facultative anaerobes, with a size from 2 to 3 by 0.4 to 0.6 microns, non-spore forming, mobile, oxidase negative and catalase positive, producing gas from D-glucose and can be used citrate as the sole source of carbon $(50,51)$. The genus is composed of two species that are $S$. bongori and S. enterica, and the latter is divided into six subspecies: enterica, salamae, arizonae, diarizonae, houtenae, and indica. S. enterica subsp. enterica includes over 1,500 serotypes, which despite their high genetic similarity vary greatly in their wide range of hosts and diseases, ranging from enteritis to typhoid fever. The degree of adaptation to the hosts varies between the serotypes of Salmonella spp and determines the pathogenicity. Serotypes adapted to humans, such as S. Typhi and S. Paratyphi A, B, C, cause systemic typhoid fever (52). The genome of Salmonella spp. contains about 4.8 to 4.9 million base pairs, with approximately 4400-5600 coding sequences (50).

One of the main pathways for Salmonella spp. transmission is contaminated water (53); therefore, the increased risks of salmonellosis are associated 
Theoretical frameworks and state of the art on the implementation of a real time PCR for the Escherichia coli quantification and Salmonella spp detection

with the ingestion of water with human or animal feces (51). Likewise, contamination with sewage, freshwater and coastal marine waters is also a source of fecal microorganisms, including Salmonella spp. $(51,54)$. In the productive field, water with presence of Salmonella spp. has the potential to contaminate fresh products such as fruits and vegetables at various points in the production cycle (55). In view of the above, it is necessary to guarantee the microbiological quality of the water from all areas in order to avoid salmonellosis outbreaks (55). The best strategy for prevention is to sample and detect this microorganism with a rapid, sensitive, specific and simple method. Several rapid detection methods have been developed to detect Salmonella spp. in water and food, including PCR. This method has significantly reduced the test time required for confirmatory results from 4-6 days to less than one day (56).

Several papers have been developed that seek the standardization and optimization of PCR for Salmonella spp. detection in water, one of them optimized the detection of $i n v A$ in drinking and surface water, this gene is indispensable for the entry of this pathogen to the epithelial cells and is used as a reference marker for Salmonella spp. by PCR. In this study it was shown that the sensitivity of PCR can be influenced by the physical dilution of the bacteria in the aquatic environments, so a culture stage must be developed before applying the technique, thus avoiding the problem of DNA amplification from dead cells, in addition to preventing the effect of PCR inhibitory substances present in water. The incorporation of a non-selective pre-enrichment step of $6 \mathrm{~h}$ incubation increased the detection limit to $26 \mathrm{CFU} / \mathrm{mL}$ in comparison to methods that not applied this step which was $2.6 \times 10^{4} \mathrm{CFU} / \mathrm{mL}$. Likewise, it was demonstrated that the development of the PCR directly on environmental waters samples did not detect Salmonella spp. But, when the PCR is performed after an enrichment step; the analyzed samples containing Salmonella spp. were positive by PCR (57). 
The PCR technique has been implemented in several studies related to water quality control. Thus, in the urban water systems of Nepal, the occurrence and diversity of Salmonella spp. serotypes was determined. The isolated Salmonelas were analyzed by PCR by the detection of the invA gene and the $s p v C$ gene, the latter encoded a virulence plasmid, important for this pathogen survival in host cells. The results of the study revealed that Salm. Paratyphi A and Salm. Typhimurium isolates were positive for the invA gene and negative for the $s p v C$ gene; however, one isolate of Salm. Typhimurium and two of Salm. Entiritidis were positive for both the invA gene and the $\operatorname{spv} C$ gene, the presence of the latter probably due to horizontal gene transfer (41).

As well, in Iran, the microbiological tap water and bottled drinking water quality was evaluated in 448 samples, making the comparison between the traditional culture method and the PCR. The culture method showed that 4 (2.77\%) of 144 tap water samples and no sample of 304 bottled drinking water samples were positive for Salmonella spp; While 5 (3.47 \%) of 144 analyzed samples of tap water were detected through PCR. Therefore, with these results it can be considered that the PCR technique has a greater precision for the detection of this bacterium in water samples (1).

Other variants of PCR have also been applied in the diagnosis of Salmonella spp. in water samples; such as multiplex PCR (m-PCR) for the detection and quantification of this bacterium simultaneously with other pathogens such as Campylobacter spp. and Escherichia coli $\mathrm{O} 157: \mathrm{H}_{7}$ in the same reaction. Specifically, for the detection of Salmonella enterica Typhimurium a pair of primers were used for the detection of the invA gene at a concentration of $960 \mathrm{nM}$. Three types of uniplex, duplex and triplex PCR were performed in the study. The quantitative modality was developed through real-time PCR using SYBR Green and determining for 
Theoretical frameworks and state of the art on the implementation of a real time PCR for the Escherichia coli quantification and Salmonella spp detection

each target a different melting temperature, which allowed distinguishing and quantifying the three pathogens at the same time in the same reaction. In uniplex PCR the detection limit for S. enterica Typhimurium was 7.33 $\mathrm{x} 10^{2}$ copies, while $\mathrm{m}$-PCR showed a detection limit of $7.33 \times 10^{3}$ copies in mixed culture samples, this could be due to the competition of primers, as well as the dimers formation (58).

The application of real-time PCR variant been carried out in home water distribution systems, where a qPCR evaluated the microbiological quality of tap water from 24 households fed from rainwater tanks in Queensland, Australia. Among the 24 households, $4 \%$ of samples from the rainwater tank contained Salmonella spp., being attributed as a possible source of contamination to bird feces (59).

Although qPCR is considered as a rapid and specific method to detect and quantify pathogens, it is unable to distinguish DNA signals that originate from living or dead cells; thus, dead cells can produce false positive results (26). To overcome these limitations, mono-acid propidium (PMA) combined with qPCR (PMA-qPCR) has been used as a strategy to achieve the most efficient exclusion of DNA amplification from dead cells. PMA is a DNA/RNA intercalation dye that can selectively penetrate through the damaged cell membrane of dead cells by covalently binding to DNA. PMA treatment is applied prior to DNA extraction, it is a simple method for the quantification of viable cells since after photoactivation it avoids the PCR amplification of genetic targets from non-viable cells (59).

The table 1 summarizes some of the PCR based techniques reported in the literature as methods for evaluating the microbiological quiality of water; where indicated the technology applied, the type of sample, the target gene, the prime or primers used and/or sequence, amplicon size and detection limit. 
REAL-TIME PCR APPLIED TO BACTERIAL WATERBORNE PATHOGENS DETECTION AND QUANTIFICATION

Table 2.1.

Salmonella spp. PCR-based techniques reported for monitoring the microbiological quality of the water

\begin{tabular}{|c|c|c|c|c|c|c|}
\hline Method & $\begin{array}{l}\text { Type of } \\
\text { sample }\end{array}$ & \begin{tabular}{|c|} 
Target \\
gen
\end{tabular} & $\begin{array}{c}\text { Primers and/or sequence } \\
\left(5^{\prime}-3^{\prime}\right)\end{array}$ & \begin{tabular}{|c|} 
Amplicon \\
size(bp)
\end{tabular} & $\begin{array}{c}\text { Detection } \\
\text { limit }\end{array}$ & Reference \\
\hline qPCR & Rain water & Inv A & $\begin{array}{l}\text { F: ACAGTGCTCGTTTACGACCTGAAT } \\
\text { R: AGACGACTGGTACTGATCGATAAT }\end{array}$ & 244 & $\begin{array}{c}7 \cdot 3 \times 10^{3} \\
\text { cells/L }\end{array}$ & (59) \\
\hline PCR & $\begin{array}{l}\text { Tap water and } \\
\text { bottled water }\end{array}$ & IpaB & $\begin{array}{l}\text { F: GGACTTTTTAAAAGCGGCGG } \\
\text { R: GCCTCTCCCAGAGCCGTCTGG }\end{array}$ & NR & NR & (1) \\
\hline PMA-PCR & $\begin{array}{l}\text { Drinking and } \\
\text { environmental } \\
\text { water }\end{array}$ & $\mathrm{ttr}$ & $\begin{array}{l}\text { F: CTCACCAGGAGATTACAACATGG } \\
\text { R: AGCTCAGACCAAAAGTGACCATC }\end{array}$ & 95 & $\begin{array}{l}1 \mathrm{CFU} / \\
\text { PCR ó } \\
10 \text { cells/ } \\
\mathrm{mL}\end{array}$ & (5) \\
\hline Multiplex-PCR & River water & 16S rDNA & $\begin{array}{l}\text { Sal-F: CGGGCCTCTTGCCATCAGGTG } \\
\text { Sal-R: CACATCCGACTTGACAGACCG }\end{array}$ & 396 & NR & (61) \\
\hline $\begin{array}{l}\text { qPCR using } \\
\text { SYBR Green }\end{array}$ & Lake water & invA & $\begin{array}{l}\text { 139: } \\
\text { GTGAAATTATCGCCACGTTCGGGCAA } \\
\text { 141: } \\
\text { TCATCGCACCGTCAAAGGAACC }\end{array}$ & 284 & $\begin{array}{l}10^{3} \text { cells } \\
\mathrm{mL}^{-1}\end{array}$ & (62) \\
\hline qPCR & $\begin{array}{l}\text { Drinking, Surface, } \\
\text { rain water and } \\
\text { treated waste water }\end{array}$ & invA & $\begin{array}{l}\text { F: CACCAAGAAGGTGACTTTATTGTG } \\
\text { R: GAACTTATAACCACCCGCG }\end{array}$ & 284 & $\begin{array}{c}1 \mathrm{CFU} / \\
\mathrm{mL}\end{array}$ & (6) \\
\hline PCR & $\begin{array}{l}\text { Raw water from } \\
\text { treatment plant }\end{array}$ & invA & $\begin{array}{l}\text { invA1: } \\
\text { ACAGTGCTCGTTTACGACCTGAAT } \\
\text { invA2 } \\
\text { AGACGACTGGTACTGATCGATAAT }\end{array}$ & 244 & $\begin{array}{l}200 \\
\text { cells/PCR }\end{array}$ & $(63)$ \\
\hline
\end{tabular}

NR: not reported. F: forward. $R$ : reverse

\section{Escherichia coli}

The enterobacteria Escherichia coli represents one of the best studied microbial organisms in the world $(64,65)$. In the year of 1885 the pediatrician German Theodor Escherich described in detail Bacterium coli commune now known as Escherichia coli in honor to his name (66). With regard to the taxonomy of this microorganism are details in table 2.2.

Table 2.2.

Taxonomy of Escherichia coli

\begin{tabular}{lc}
\hline & Taxonomia E. Coli \\
\hline Domain: & Bacteria \\
\hline Kingdom: & Eubacteria \\
Phylum: & Proteobacteria \\
Class: & Gammaproteobacteria \\
Order: & Enterobacteriales \\
Family: & Enterobacteriaceae \\
Genus: & Escherichia \\
Specie: & E. coli \\
\hline
\end{tabular}

Source: Second edition of the handbook of bergey's (67). 
Theoretical frameworks and state of the art on the implementation of a real time PCR for the Escherichia coli quantification and Salmonella spp detection

E. coli is a gram-negative bacterium in the form of straight cylindrical rods of 1.1 -1.5 $\mu \mathrm{m}$ in diameter and 2.0 - 6.0 $\mu \mathrm{m}$ in length can be alone or in pairs and have mobility by perimeter flagella, although some strains are not motile. E. coli strains are catalase positive and oxidase-negative fermenters of glucose with gas production and most also use lactose, except for some serotypes such as E. coli O157:H7. It is able to grow both aerobically and anaerobically, with a wide temperature range between $15-45^{\circ} \mathrm{C}$ and an optimum temperature of $37^{\circ} \mathrm{C}$. This bacterium have a pH between $5-9$, which confers resistance to adverse environmental conditions $(68,69)$.

According to Van Elsas and collaborators, data suggest that E. coli may persist for varying periods of time in terrestrial and aquatic habitats, which is why an important aspect of some strains of $E$. coli is their ability to acquire nutrients producing structures filaments that extend from the cell surface and allow the cell to adhere to plant surfaces, it is thanks to this peculiarity that $E$. coli from contaminated soils, manure, irrigation water or seeds can colonize some plants such as radish or Lettuce. Pathogenic strains of E. coli, such as E. coli $\mathrm{O} 157: \mathrm{H}_{7}$, represent a threat to the food chain and an environmental risk still underestimated (70).

The size of the $E$. coli genome varies between 4.6-5.5 Mb (millions of base pairs) depending on the strain and the serotype. For example: for strain $\mathrm{K} 12$ is 4,639,221 base pairs (pb) and the chromosome of strain $\mathrm{O} 157: \mathrm{H} 7$ has 5,528,445 bp being the largest size (71).

E. coli is present in the normal microbiota of the intestine of humans and animals, but of the strains of $E$. coli are not pathogenic and live harmLessly in the colon; Although in some cases E. coli may become an opportunistic pathogen in immunocompromised individuals; however, it should be noted that some serotypes or clones can cause intestinal and extraintestinal diseases in healthy people due to a series of virulence factors (69). 
These virulence attributes are frequently coded in mobile genetic elements such as transposons, plasmids, pathogenicity islands or phages that can be mobilized between the different strains by horizontal gene transfer to create new variants of virulence factors or in some cases these genetic elements, that in some time they were mobile have, evolved to become part of their genome. These factors of virulence have persisted in some strains and have become 'Pathotypes' of E. coli, as is the case of the famous serotype $\mathrm{O} 157: \mathrm{H} 7$ or others less common as the variant of $E$. coli $\mathrm{O}_{104}: \mathrm{H}_{4}$ capable of causing diseases in healthy individuals $(64,72,73)$; but without a doubt as to public health the most important serotype is E. coli $\mathrm{O} 157: \mathrm{H}_{7}$ which was first isolated in 1975 (74).

A large part of these pathotypes cause public health problems and high morbidity and mortality throughout the world. This is because they have low infectious doses and are transmitted through ubiquitous media, including food and water. Outbreaks are common in both developed and underdeveloped countries, sometimes the final resolution of the disease has fatal outcomes; hence the importance of international and national surveillance programs for $E$. coli infections in humans, animals, food and the environment $(68,75)$.

There are six main diarrheogenic E. coli pathophyses: enterohaemorrhagic E. coli (EHEC), enteropathogenic E. coli (EPEC), enterotoxigenic E. coli (ETEC), enteroinvasive E. coli (EIEC), enteroaggregative $E$. coli (EAggEC) and Diffuse adhesion E. coli (DAEC) (76).

Recently, new strains have been described as the case of the EPEC/ETEC hybrid strain in a child with acute diarrea (77) and in patients with hemolytic uremic syndrome and diarrhea the STEC/ETEC hybrid (70) and the particular case of a shigatoxin-producing E. coli identified in Germany that 
Theoretical frameworks and state of the art on the implementation of a real time PCR for the Escherichia coli quantification and Salmonella spp detection

caused one of the largest outbreaks of uremic-hemolytic syndrome in the world, with the suggestion of the name of $E$. coli entero-aggregative-hemorrhagic (EAHEC), thus demonstrating the plasticity of the $E$. coli genome (67).

There is enormous diversity within the species, which differs in subgroups based on various physiological, morphological and antigenic characteristics (65). E. coli has four surface antigens, although it is true that polysaccharide $\mathrm{O}$ and flagellin are the two major antigens of gram-negative bacteria, also known respectively as antigens $\mathrm{O}$ and $\mathrm{H}$ (79), the capsular antigen $(\mathrm{K})$ and Fimbrial antigen (F) have also been used to serotype strains (80).

Classical serotyping is based on the Kauffman classification scheme, where polysaccharides $(\mathrm{O})$ (somatic), surface antigens $(\mathrm{H})$ (flagellar) and capsular antigens (K) are determined (81). Molecular methods such as PCR, where the identification of genes involved in the biogenesis of antigen $(\mathrm{O})$ (eg, wzx and wzy genes) and flic for antigen $(\mathrm{H})$, can also be used to identify the serotype $(65,68)$.

There is an extensive genetic substructure within Escherichia coli species. Clermont and collaborators described a triplex PCR where $E$. coli isolates fit into one of four known A, B1, B2 or D phylogroups (82) but in $2012 \mathrm{Cl}-$ ermont developed a new method based on a quadruplex PCR that allows to assign an isolation of $E$. coli to one of the eight phylogroups that are currently recognized: seven (A, B1, B2, C, D, E, F) belong to E. coli Sensu stricto while the eighth is the Escherichia cryptic clade I. This new differentiation between strains occurred due to increasing body data from multiple locus sequences and genome data for $E$. coli. This new quadruplicate PCR allows correctly assigning more than $95 \%$ of the isolates of $E$. coli to a phylogroup (83). 
Traditional culture methods for pathogenic E. coli serotypes are time consuming and laborious. For this reason, molecular techniques that allow a faster identification of the different pathotypes (68) are commonly used today; thus the available evidence suggests that the chromogenic means for the detection of strains of the Shigatoxigenic Escherichia coli (STEC) group do not have sufficient sensitivity or specificity to replace methods that directly detect toxin or toxin genes in samples. Accordingly, most Perry (2017) studies have concluded that the optimal use of such media is for the isolation of STEC from samples that are determined to be positive using more sensitive methods of detection, eg PCR (84).

The table 2.3 summarizes some of the PCR-based techniques reported in the literature as methods for evaluating the microbiological quality of water, selected because of the interesting approaches used in the development of a new protocol or the promising results obtained. The technology applied, the type of sample, the target gene, the primer or primers used and/or the sequence, amplicon size and detection limit are indicated. 
Theoretical frameworks and state of the art on the implementation of a real time PCR for the Escherichia coli quantification and Salmonella spp detection

Tabla 2.3.

E. coli PCR-based methods for monitoring the microbiological quality of the water

\begin{tabular}{|c|c|c|c|c|c|c|}
\hline $\begin{array}{l}\text { Type of } \\
\text { PCR }\end{array}$ & $\begin{array}{l}\text { Type of } \\
\text { sample }\end{array}$ & $\begin{array}{l}\text { Target } \\
\text { gene }\end{array}$ & Primer sequence $(5 \rightarrow 3)$ & $\begin{array}{l}\text { Amplicon } \\
\text { size (bp) }\end{array}$ & $\begin{array}{l}\text { Detection } \\
\text { limit }\end{array}$ & $\begin{array}{l}\text { Refe- } \\
\text { rence }\end{array}$ \\
\hline \multirow{7}{*}{$\begin{array}{l}\text { Multiplex } \\
\text { PCR }\end{array}$} & \multirow{7}{*}{ Water samples } & aaiC & $\begin{array}{l}\text { F: AGAGCGTCCACTGTCAGAGCGT } \\
\text { R: GCGACCTGCTCTGGCGTGAAAT }\end{array}$ & 183 & \multirow{7}{*}{$5.2 \mathrm{ng} / \mu \mathrm{L}$} & \multirow{7}{*}{ (85) } \\
\hline & & escV & $\begin{array}{l}\text { F: TAACGCCTGCGCGCATATCACC } \\
\text { R: GTTGATGCGCCTGTCGCTAGT }\end{array}$ & 266 & & \\
\hline & & bfpA & $\begin{array}{l}\text { F: TCTGCAATGGTGCTTGCGCTTG } \\
\text { R: CAGTTGCCGCTTCAGCAGGAGT }\end{array}$ & 478 & & \\
\hline & & stx1 & $\begin{array}{l}\text { F: AGCGATGCAGCTATTAATAA } \\
\text { R: GAAGAGTCCGTGGGATTACG }\end{array}$ & 130 & & \\
\hline & & $\mathrm{ipaH}$ & $\begin{array}{l}\text { F: CAGGTCGCTGCATGGCTGGAAA } \\
\text { R: GGCAGTGCGGAGGTCATTTGCT }\end{array}$ & 383 & & \\
\hline & & stx2 & $\begin{array}{l}\text { F: TTAACCACACCCCACCGGGCAGT } \\
\text { R: GCTCGGATGCATCTCTGGT }\end{array}$ & 346 & & \\
\hline & & Elt & $\begin{array}{l}\text { F: AGGCGTATACAGCCCTCACCCA } \\
\text { R: ACCTGAAATGTTGCGCCGCTCT }\end{array}$ & 550 & & \\
\hline \multirow[b]{2}{*}{$\begin{array}{l}\text { Multiplex } \\
\text { PCR }\end{array}$} & \multirow{2}{*}{$\begin{array}{l}\text { Artificial } \\
\text { water samples } \\
\text { and Sample } \\
\text { city water } \\
\text { distribution } \\
\text { network }\end{array}$} & uidA & $\begin{array}{l}\text { UAL: TGGTAATTACCGACGAAAACGG } \\
\text { UAR: ACGCGTGGTTACAGTCTTGCG }\end{array}$ & 147 & \multirow[b]{2}{*}{ NR } & \multirow[b]{2}{*}{ (86) } \\
\hline & & lacZ & $\begin{array}{l}\text { LZL-F: ATGAAAGCTGGCTACAGGAAGGCC } \\
\text { LZR-R: CACCATGCCGTGGGTTCAATATT }\end{array}$ & 876 & & \\
\hline $\begin{array}{l}\text { qPCR and } \\
\text { PMA-qPCR }\end{array}$ & $\begin{array}{l}\text { Drinking and } \\
\text { process water } \\
\text { samples }\end{array}$ & uidA & $\begin{array}{l}\text { ECN1254-F: GCAAGGTGCACGGGAATATT } \\
\text { ECN1328-R: CAGGTGATCGGACGCGT }\end{array}$ & 75 & $\begin{array}{c}12-120 \\
\text { bacterial cells }\end{array}$ & $(87)$ \\
\hline \multirow{5}{*}{$\begin{array}{l}\text { Multiplex } \\
\text { PMA-qPCR }\end{array}$} & \multirow{5}{*}{$\begin{array}{l}\text { Irrigation } \\
\text { water }\end{array}$} & stx1 & $\begin{array}{l}\text { stx1-F GACTTCTCGACTGCAAAGAC } \\
\text { stx1-R TGTAACCGCTGTTGTACCTG }\end{array}$ & 306 & \multirow{5}{*}{$\begin{array}{c}1 \mathrm{CFU} / \mathrm{100} \\
\mathrm{mL}\end{array}$} & \multirow{5}{*}{ (88) } \\
\hline & & stx2 & $\begin{array}{l}\text { stx2-F CCCGGGAGTTTACGATAGAC } \\
\text { stx2-R ACGCAGAACTGCTCTGGATG }\end{array}$ & 482 & & \\
\hline & & eae & $\begin{array}{l}\text { eae-F GCGCGTTACATTGACTCCCG } \\
\text { eae-R CCATTTGCTGGGCGCTCATC }\end{array}$ & 245 & & \\
\hline & & ehxA & $\begin{array}{l}\text { ehxA-F TCTGTATCTGCGGGAGTTAG } \\
\text { ehxA-R CAACGTGCTCAAACATAGCC }\end{array}$ & 136 & & \\
\hline & & uidA & $\begin{array}{l}\text { PT-2 GCGAAAACTGTGGAATTGGG } \\
\text { uidA-R TCGTCGGTAATCACCATTCC }\end{array}$ & 382 & & \\
\hline
\end{tabular}

NR: Not Reported. F: Forward. R: Reverse

\footnotetext{
How to quote this chapter:

Bolívar Anillo H, Soto Varela Z, Orozco Sánchez C, Pichón González C, Granados Pantoja B. Theoretical bases and state of the art on the implementation of a real time PCR for the Escherichia coli quantification and Sallmonella spp detection. In Badillo Viloria M, Pérez Lavalle L, editors. Real-time PCR applied to bacterial waterborne pathogens detection and quantification. Barranquilla: Ediciones Universidad Simón Bolívar; 2018. p. 19-39.
} 